\title{
PEREIRA, CLÁUdiA GOMES. \\ CONTESTADO FRUTO: A POESIA ESQUECIDA DE BEATRIZ BRANDÃo (1779- 1868). LISBOA: CLEPUL, 2011, 358 P.
}

As palavras são entidades mágicas e instigantes. Certa feita, escrevi uma monografia de final de disciplina, no mestrado, utilizando apenas dicionários: da língua portuguesa, de símbolos, de filosofia... Desde então, é mais que delicioso passear pelos verbetes dicionarizados e descobrir sentidos outros, provocações, consolidar constatações. Isso é exatamente o que acontece com estas duas palavras: contestação e estratégia. A primeira, ato de contestar, arrasta em sua maré semântica as ideias de contradição e de impugnação. A primeira ideia, mais afeita ao meu propósito aqui, serve de referência para sustentar a afirmativa de que não há, de fato, contradição no texto que apresento. Antes, a contradição se estabelece em relação ao efeito da ausência de leitura da obra da escritora mineira, objeto de desejo da autora do livro. Na rubrica "jurídica", a mesma palavra identifica um "escrito no qual o réu da ação contraria o pedido do autor (O direito de ação, que visa à tutela jurisdicional do Estado, é exercido pelo réu valendo-se da contestação)." Não é bem o caso aqui, mas ajuda a esclarecer possível dúvida: a poetisa, antes mesmo de ser "julgada", parece ter sido "condenada" a fazer parte do rol de contrariedades que leitoras como a Cláudia causam a certo cânone, infringindo seu status quo por erigir a imagem de um sujeito que se destaca, ainda que contra a maré... Claro está que a sombra do pensamento de Foucault se faz sentir aqui, sem a explícita necessidade de apontar onde e quando ela se manifesta. $O$ pensamento de Foucault é que se faz permeado pelo discurso da autora do livro aqui resenhado. Arriscaria a dizer que em $O$ que é um autor este caminho far-se-ia um tanto menos tortuoso.

Por sua vez, estratégia é palavra que se circunscreve, inicialmente, à semântica da linguagem militar. É entendida como arte de coordenar a ação das forças militares, políticas, econômicas e morais implicadas na condução de um conflito ou na preparação da defesa de uma nação ou comunidade de nações, ou ainda, como parte da arte militar que trata das operações e movimentos de um exército, até chegar, em condições vantajosas, à presença do inimigo. Pensando belicamente, poder-se-ia deduzir que o termo não se "aplica" ao que pretendo aqui. No entanto, caminhando um pouco mais pelo verbete, encontra-se outra acepção que aponta para a ideia de arte de aplicar com eficácia os recursos de que se dispõe ou de explorar as condições favo- 
ráveis de que porventura se desfrute, visando ao alcance de determinados objetivos, que é complementada, ainda como extensão de sentido, por outra: ardil engenhoso; estratagema, subterfúgio.

Com a conclusão do segundo parágrafo, penso, chego no ponto que pretendia chegar para dar início a meus comentários. Explico-me. Da leitura de suas 358 páginas, o livro de Cláudia Gomes Pereira é a mais acabada, densa, consistente, pertinente e instigante demonstração de como "aplicar com eficácia os recursos de que se dispõe ou de explorar as condições favoráveis de que porventura se desfrute". Orientada por metodologia de viés etnográfico, Cláudia persegue a obra da poetisa ouro-pretana aqui e além mar. Em seu perímetro a investigação persegue o manancial quase infinito de abordagem consolidado pelas ideias da Estética da recepção.

Estas duas referências são necessárias para alcançar o grau de profundidade que a leitura de Cláudia faz da obra de Beatriz Brandão. Neste sentido, o comparatismo comparece na confluência das vertentes histórica e crítica que delineiam o caminho traçado pela tese defendida por Cláudia em seu livro. O tempo que ela levou em sua elaboração - um mestrado, um doutorado e um estágio pós-doutoral, assim mesmo, em seguida - foi suficiente para o esboço do mapa, o percurso do caminho e o encontro de seu ponto de chegada. Neste sentido, a dissertação - que já demonstrava os caminhos que seguiria depois - apresentou parte do corpus poético de Beatriz Brandão, acompanhado de um estudo introdutório sobre sua poética. Àquela altura, lembro-me - fui membro titular da banca de defesa da dissertação - comentou-se sobre a argúcia da mestranda e das potencialidades de seu trabalho que poderia, de uma vez por todas, resgatar a poetisa e sua obra, fazendo-a destacar-se para muito além das alterosas.

A tese, que resultou no livro ora apresentado, é prova disso. Seu objetivo, portanto, estrategicamente, foi alcançado. $O$ trabalho de mestrado e doutorado é coroado com a recolha da obra de Beatriz Brandão. Tal feito confere ao presente livro um caráter de "edição" da poesia de Beatriz Brandão. Mais uma possibilidade de abordagem deste trabalho, então, se apresenta: a crítica genética. Digo isso longe de reduzir o trabalho de Cláudia, mas apontando para o leitor mais um "atalho" em sua demanda direcionada ao cerne da pesquisa. Aos poucos, vai-se percebendo a localização dos pontos de ancoragem do processo de composição da poesia de Beatriz.

Faltaria explicar o "estratagema", o "subterfúgio" - termos que fecham o verbete da palavra "estratégia", origem do adjetivo que utilizo para operacionalizar minha apresentação. Este(s) não se reduz(em) a meras estripulias protocolares que tentam abrir atalho em busca de um ponto de fuga que desonerasse a autora de sua responsabilidade. Assim, vale destacar que os desdobramentos do projeto de Cláudia "ultrapassam o mero interesse que 
poderá ter a identificação de (mais) uma autora: sublinham a necessidade de interrogar os silêncios da História, de olhar para além das representações veiculadas pelo discurso da historiografia iteraria tradicional, evidenciam as limitações do nosso conhecimento sobre a verdadeira dimensão da presença de mulheres brasileiras no campo cultural antes do século XX, e chamam a atenção para a complexidade e para a vitalidade da vida intelectual, da cultura letrada e da circulação de ideias, de textos e de livros no Brasil-Colónia, e no Brasil-nação dos primeiros tempos da sua independência." Tudo isto é muito bem apontado por Vanda Anastácio, professora da Faculdade de Letras da Universidade de Lisboa que prefacia o volume.

o que diz a professora portuguesa não é pouco e pode ser contatado pela leitura do livro de Cláudia. Nele, a autora organiza a matéria de forma a consolidar os resultados de sua investigação; neste aspecto, contribui para a faceta contestatória que mencionei acima. A matéria se encontra dividida em quatro grandes blocos: "A escrita de autoria feminina no Brasil dos séculos XVIII e XIX", "A produção literária de Beatriz Brandão no contexto oitocentista", "Contestado fruto: a poesia esquecida de Beatriz Brandão", "Bibliografias" e "Anexos". Pode parecer comum e corriqueiro, mas não é. Como resultado de pesquisa para escrita de tese de doutoramento, o "produto" final ultrapassa, e muito, estes limites. O maior número de páginas do volume é dedicado a apresentar a produção poética de Beatriz Brandão, deixando a menor parte para o chamado arcabouço teórico. Na verdade, chega a ser falso afirmar isso, dado que os dois primeiros capítulos funcionam como esboço de território por onde a autora deixa transparecer a poesia, seu objeto de desejo. Os dois últimos capítulos constituem matéria apensa que tem a finalidade de "documentar" seu percurso, deixando ao leitor a tarefa de fazer as devidas e possíveis ilações no desenvolvimento da leitura. Parece-me que este "modelo" contesta o que se tem visto por aí em termos de escrita acadêmica meramente protocolar. A provocação que daí tem efeito é por demais prazerosa, dado que a poesia que se apresenta prescinde de qualquer "amparo" teórico. Ela fala por si. Nesta direção, Cláudia não deixa de embarcar na viagem da redescoberta pela leitura.

No lugar de indicar para o leitor o que e como ler, montando equações teóricas que poderiam, exegeticamente, "explicar" a situação da poetisa estudada, Cláudia deixa que sua poesia se desnude, provocando o leitor a acompanhar seus movimentos. Com o amparo das correspondências - material que constitui parte do terceiro capítulo do livro - esta mesma leitura é enriquecida, ainda uma vez sob o efeito do exercício de leitura a que cada um de nós é convidado a fazer. De novo, o espírito de contestação se deixa perceber. De fato, as circunstâncias que personalizam a presença - na verdade, quase absoluta ausência - de Beatriz Brandão em qualquer cânone da 
Literatura Brasileira, demonstram a força de sua poesia e a relutância em aceder ao poderio androcêntrico e patriarcalista que marcam a História da cultura no Brasil, sobretudo no período de existência da poetisa de Ouro Preto.

Somente pela imaginação e, talvez, por um ou outro "documento" é possível ter uma ideia do que significou ser mulher nos séculos XVIII e XIX em Minas Gerais e, por que não dizer, no mundo. Guardadas as idiossincrasias culturais de cada povo, cada cultura, o "ser mulher" parece se erigir sobre uma mesma base. $O$ desenho desta é semelhante na arquitetura moral, ainda que se diferencie no "acabamento" exterior. Cláudia parece acompanhar este movimento quando opta por "apresentar" Beatriz Brandão e sua poesia, em lugar de esmiuçar possíveis desdobramentos semânticos para os seus versos. Antes de sua investigação, cujo resultado aqui se apresenta, a vida e a obra de Beatriz Francisca de Assis Brandão, nascida na Freguesia de Nossa Senhora do Pilar de Ouro Preto e, na matriz homônima, batizada em 12 de Agosto de 1779 - ainda permanecem dúvidas quanto à exatidão da data de nascimento da poetisa -, sobreviviam cobertas pela pátina do tempo, recoberta pelo manto do desconhecimento. Esta cobertura é retirada pelo gesto ousado de Cláudia.

Como afirma Constância Lima Duarte, professora da Universidade Federal de Minas Gerais, a respeito do perfil de Beatriz Brandão, no posfácio da obra, "A esmerada educação que recebeu permitiu que se destacasse como poetisa, musicista e também como tradutora de italiano e francês. Enquanto a maioria avassaladora das mulheres brasileiras vivia reclusa, analfabeta e submetida a diferentes preconceitos, Beatriz Brandão escrevia livros e mantinha escolas para meninas (...). Aliás, ela foi uma das primeiras a se submeter ao exame público para o cargo de mestra em Minas Gerais, no ano de 1830. Tantas distinções levaram o historiador Joaquim Norberto de Souza Silva, em 1850, a propor a inclusão de seu nome para membro do Instituto Histórico e Geográfico Brasileiro, o que naturalmente não foi aceito por ela ser mulher, apesar de seus reconhecidos méritos." (p. 357)

Indubitavelmente, uma contestadora. Personalidade forte e um tanto à frente de seu tempo, Beatriz Brandão não se curvou à imbecilidade dos preconceitos e contestou o posicionamento imposto pela cultura da sociedade em que se criou e viveu. Da mesma forma, Cláudia Pereira Gomes, ao escrever sobre a poetisa mineira, o faz de maneira contestatória. Tanto pela eleição metodológica feita, quanto pela galhardia com que desenvolve e defende seu projeto, fruto de trabalho profícuo, sério, apaixonado e atento, o que a levou a alcançar seu doutoramento. No estágio pós-doutoral, realizado em Lisboa, acompanhada por Vanda Anastácio e Vânia Chaves, Cláudia veio a corroborar, uma vez mais, sua capacidade intelectual, sua paixão pelos estudos literários e sua devoção à poesia de Beatriz Branda. Em tudo e por 
tudo, o livro é fruto da anunciada contestação como estratégia. Falta agora a companhia de mais leitores... Evoé, Cláudia!

José Luiz Foureaux de Souza Júnior

Universidade Federal de Ouro Preto

Submetido em: 25/01/2013

Aceito em: 07/10/2014 